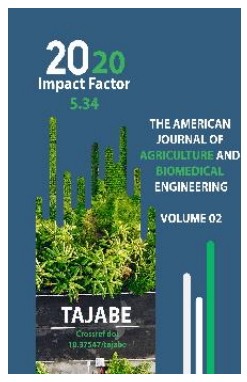

\section{Studying Non-Traditional Plants Oils For Food Purpose}

\author{
Akramova Rano Ramizitdinovna \\ PhD, Associate Professor Of The Department Of Food Technology, Tashkent Institute Of \\ Chemical Technology, Uzbekistan \\ Sayfutdinov Djamolitdin Ramizitdinovich \\ Post Doctoral Of The Department Of Food Technology, Tashkent Institute Of Chemical \\ Technology, Uzbekistan
}

\title{
ABSTRACT
}

The article discusses the possibility of expanding the range of strategically important consumer food products such as vegetable oil.The necessity of developing an innovative technology for obtaining non-traditional vegetable oils, which will improve the economic mechanism for the development of the food market, has been substantiated. The physical and chemical characteristics of oil seeds grown in Uzbekistan have been studied. It has been proven that the oils obtained from non-traditional oilseeds can be used for consumption, and will play an important role in expanding the range of nontraditional vegetable oils.

\section{KEYWORDS}

Non-traditional oilseeds, corn germ, wheat germ, non-traditional oils, wheat germ oil, corn germ oil, physicochemical composition of oils.

\section{INTRODUCTION}

It is known that over the years of independence Uzbekistan began to produce more than 7.639 million tons of wheat grain annually. Of these, 4-6\% are high-oily germ, rich in provitamin $\mathrm{E}$ (tocopherol) and other biologically useful substances. 
Fat-and-oil enterprises of the Republic are mainly built for processing cotton seeds according to the "pre-pressing-extraction" scheme and for processing wheat germ, they require reconstruction and improvement in a known technology, taking into account the peculiarities of germs obtained from local wheat varieties.

The complexity of the problem of the production of oil from wheat germ is to obtain an easily compressible and easily extractable structure of the material. the petal obtained from the germ of wheat grain has high elasticity and dispersion.

Rice husk, a waste of rice grain processing, needs rational use and therefore its use as a binder and a structure of the forming substance in the composition of the germ of wheat grain undoubtedly contributes to an increase in the technical and economic indicators of oil and fat and grain processing industries.

Thus, the improvement of the technology for obtaining oil from the germ of grain of local wheat varieties using rice husks and a pellet press is an urgent task of scientific and practical importance.

The degree of knowledge of the problem. Literary review and analysis of works devoted to the production of oil from the germ of wheat, corn, etc. showed that today, due to the low efficiency of known technologies, such products are not produced in fat-and-oil enterprises. The germ formed at grain processing plants are sent to the production of compound feed, which, in our opinion, is not considered rational.

Previously, VNIIZH developed a technology for the production of oils from the germ and bran of cereal crops, which is mainly aimed at the extraction of the obtained cake in immersion devices (ND-1000, etc.).

Research results. The technology proposed by the scientists of the Bukhara Technological Institute of Food and Light Industry requires the use of special equipment and reagents for processing embryo materials. Although biotechnological methods increase the yield of pressing oil by several units, they greatly overestimate the cost of their production. they additionally use expensive reagents.

Works on obtaining oil from wheat germ by granulating them using rice husks have not been found in the literature.

Table 1.1. some types of oilseeds are presented, containing the germs of the main types of oilcontaining raw materials.

\section{Table 1.1.}

\section{Physicochemical indicators and lipid content in oils obtained from the germ of some oilseeds}

\begin{tabular}{|c|c|c|c|c|}
\hline Nameofculture & $\begin{array}{c}\text { Density at 15 } \\
{ }^{\circ} \mathrm{C}, \mathrm{kg} / \mathrm{m}^{3}\end{array}$ & $\begin{array}{c}\text { Refractiveindex, } \\
\text { at 20 }{ }^{\circ} \mathrm{C}\end{array}$ & Pourpoint, ${ }^{\circ} \mathrm{C}$ & $\begin{array}{c}\text { Lipidcontent, } \\
\%\end{array}$ \\
\hline Wheat & $924-946$ & $1,469-1,476$ & about 0 & $7-8$ \\
\hline Corn & $924-926$ & $1,471-1,474$ & $-10:-20$ & $18-30$ \\
\hline
\end{tabular}


The germ and bran of cereal grain are of practical value in terms of volume / 24.84 /. The large scale of modern large-scale flour-milling, corn processing industries allows to concentrate this waste in large quantities. With proper organization of collection and storage, they represent a significant additional source for the production of vegetable oils, the demand for which increases every year.
Oilseed semi-finished products in food enterprises, as it is correct, are separated after destruction or damage to the cellular structure of cereals. Thus, the germ of cereal crops can be isolated from flour or cereals only after mechanical destruction of grain tissues.

Table 1.2 shows the yield of germ from grain crops, as well as the content of lipids in them.

\section{Table 1.2}

\section{Germ Yields and Lipid Content in Main Cereals}

\begin{tabular}{|c|c|c|c|}
\hline \multirow{2}{*}{ Name of culture } & \multicolumn{2}{|c|}{$\begin{array}{c}\text { Lipid content\% in terms of } \\
\text { on dry matter }\end{array}$} & \multirow{2}{*}{$\begin{array}{c}\text { Germ yields, \% } \\
\text { grainmass }\end{array}$} \\
\cline { 2 - 3 } & wholegrain & in germ & \\
\hline Rice & $2,0-3,2$ & $24-25$ & $8-16$ \\
\hline Corn & $3,6-12,0$ & $30-48$ & 12 \\
\hline Wheat & I, 9-2,8 & $10-17$ & 2 \\
\hline Rye & I, 7-2,6 & $11-13$ & 2 \\
\hline Millet & $2,5-7,3$ & до 27 & 1,5 \\
\hline
\end{tabular}

From table. 1.2 it can be seen that the highest yield of germ is observed during the processing of rice and corn, and wheat has more than $2 \%$ of the yield of germ.

For the production of non-rancid, shelf-stable / 7.8 / flour from wheat and rye, the germ after grinding the grain must be separated from flour in the form of bran. Their complete separation is practically impossible, and endosperm particles, as well as some amounts of membranes, enter the mass of germ. The endosperm of the grain is represented by substances of a protein and carbohydrate nature and contains significantly less oil than the embryo. Wheat and rye grain casings contain up to $5-6 \%$ oil.

Wheat bran with modern varietal grinding in the average make up $18 \%$ of the mass of processed grain. Their chemical composition depends, on the one hand, on the chemical composition of the grain, and on the other, on the features of the technological process for the production of high-quality flour.

Fractional composition of wheat bran (\% mass): shell - 30, mealy endosperm - 35, aleurone layer of endosperm - 30 , germ - 5 .

Fatty acid composition and physicochemical properties of oils obtained during the processing of grain germs are presented in table 1.3. / 133, 158, 160/.

In terms of lipid composition, the oils extracted from the germ of grain crops are close to the lipids of fruit and seed coats of oil plants. With the complex use of this type of oilseed raw material, it is possible to obtain edible oil, fodder meal rich in easily digestible protein groups and essential amino acids, as well as vegetable waxes. 
Consequently, the analysis of vegetable oilbearing raw materials currently used by the oiland-fat industry indicates an exceptional variety of its chemical composition, properties and technological characteristics. The most important common feature that makes it possible to classify plant materials as oilseeds is the relatively high content of easily extractable lipids. The wide variation of this indicator in oil seeds and fruits reveals some general regularities that are valid for most of the oil plants.

One of the main indicators of vegetable oils is their fatty acid composition, which is currently determined by the chromatographic method. Based on the results of this analysis, it is possible to classify vegetable oils into: highly saturated and unsaturated.

Liquid chromatography is increasingly being used as an analytical method in pharmacopoeial analysis. Also, we have studied the fatty acid composition of the germ of cereal crops using GLC and mass spectrophotography.

Table 1.3 shows the fatty acid composition of oils obtained from the germ of cereals.

\section{Table 1.3}

Fatty acid composition of oils obtained from germ

cereals.

\begin{tabular}{|c|c|c|}
\hline $\begin{array}{c}\text { Fatcontent } \\
\text { acids, } \%\end{array}$ & Wheatgerm & Corn germ \\
\hline$C_{14: 0}$ & 0,2 & $0,1-1,7$ \\
\hline$C_{16: 0}$ & $7-18$ & $8-11$ \\
\hline$C_{18: 0}$ & $1-6$ & $2,5-4,5$ \\
\hline$C_{20: 0}$ & 0,7 & 0,4 \\
\hline$C_{22: 0}$ & 0,2 & 0,2 \\
\hline$C_{16: 1}$ & 1,0 & $0,2-1,6$ \\
\hline$C_{18: 1}$ & $8-30$ & $30-49$ \\
\hline$C_{18: 2}$ & $44-65$ & $40-56$ \\
\hline$C_{18: 3}$ & $4-10$ & - \\
\hline
\end{tabular}

As you can see from the table. 1.3 the germcontain a large amount of palmitic, linoleic and oleic acids, which confirms their closeness to traditional vegetable (sunflower, soybean and cottonseed) oils.

\section{DISCUSSION}

Based on the analyzes of the studies, the oil obtained from non-traditional oilseeds grown in Uzbekistan meets the requirements for

composition and quality parameters. It has been proven that oil of oilseeds from local varieties contains irreplaceable monounsaturated (oleic acid), polyunsaturated (omega-6) fatty acids, tocopherols and other useful substances. 
The above results indicate that the obtained unconventional oils are recommended for functional nutrition for wide use as salad oil, as well as for use in cosmetics.

\section{REFERENCES}

1. Vereshchagin I.A., Krasnok N.P., Bukhtoyarova Z.T. Electron microscopic study of the structural organization of storage substances in the embryos of rice caryopsis with loss of viability // Fiziol. plants. -1979.-t. 26.Issue 4.-s750-755. I

2. Maslikov V.A. Technological equipment for the production of vegetable oils. - $M$ : Food industry. 1974. p. 439.

3. Prokofiev A.A. Some physiological features of fruits and seeds of oil plants. -In collection: Biological bases for improving the sowing material of agricultural crops. $-M$.: Science. -1964 . -from. 15-17.

4. Mirzakarimov R.M. Research and improvement of the technology of extraction of cotton and stone seeds. 392.

5. Development of technology for the production of vegetable oil from germ flakes of wheat. R. A. Makhmudov, R.B. Rakhimov, K.H. Mazhidov. // Yosholimlarvatalabalarning II Republic of Ilmiy-conference tezislariteplami, Toshkent, 1996, $61 \mathrm{~b}$.

6. Fatty acid and triacylglycerol compositions of wheat germ flakes oil. K.Kh. Mazhidov, R.A. Makhmudov, Yu.I. Makienko. // Chemistry of natural compounds, Tashkent, 1996, No. 2,

7. Katsuhisa Ya. Et al. Obtaining fat-free corn germs // Konai also koho. 1990.

8. Wild H., Eggers R. Hochdruckextraktionzurmehrstufunge rfraktionlerender

Separation
zurschonendenGewinnung von KelmolenmithochverdichtetemKohlen dioxid//Fett Wiss. Technol. 1991. №9.

9. Daftary R.D., Pomeranz J. Changes in lipid cjmposition in wheat during storage deterioration. - Agric.Food Chem. - 1965. - №13. - p.442-446.

10. Paul A.K., Mukherji S., Sircan S. Metabolism chages in rice seeds during storage. - Yndian J. Agric.Sci. - 1970. № 40. - p.1031-1036. 